\title{
Effect of Heat Treatment on Microstructure and Mechanical Properties of Mg-5Zn-1Mn Alloy Tube
}

\author{
Lianhui Li ${ }^{1}$, Hongshuai Cao ${ }^{1}$, Fugang $\mathrm{Qi}^{1}{ }^{1 *} * \mathbb{D}$, Qing Wang ${ }^{2}$, Nie Zhao ${ }^{1}$, Yingdu Liu ${ }^{1, *}$, Xue Ye ${ }^{1}$ \\ and Xiaoping Ouyang ${ }^{1}$ \\ 1 School of Materials Science and Engineering, Xiangtan University, Xiangtan 411105, China; \\ lilianhui_123@163.com (L.L.); caohongshuai@aliyun.com (H.C.); zhaonie@xtu.edu.cn (N.Z.); \\ yexue2201@163.com (X.Y.); oyxp2003@aliyun.com (X.O.) \\ 2 China Railway Eryuan Engineering Group Co. Ltd., Chengdu 610000, China; wqctgu0119@126.com \\ * Correspondence: qifugang@xtu.edu.cn (F.Q.); liuyingdu@xtu.edu.cn (Y.L.); Tel.: +86-731-5829-8119 (F.Q.)
}

Received: 21 January 2020; Accepted: 25 February 2020; Published: 26 February 2020

\begin{abstract}
The effects of heat treatment on the microstructure, mechanical properties and electrochemical property of the as-extruded Mg-5Zn-1Mn (ZM51) alloy tube are investigated by optical microstructure (OM), X-ray diffractometer (XRD), scanning electron microscopy (SEM), transmission electrical microscope (TEM), uniaxial tensile test, and electrochemical test. The results show that the as-cast structure is a typical dendritic structure, mainly composed of $\alpha-\mathrm{Mg}$ and $\mathrm{Mg}_{7} \mathrm{Zn}_{3}$ eutectic compounds. After homogenization, most of $\mathrm{Mg}_{7} \mathrm{Zn}_{3}$ eutectic phases are dissolved in the $\mathrm{Mg}$ matrix. During the extrusion process, the ZM51 alloy has undergone complete dynamic recrystallization and has a good elongation, reaching $21.4 \%$. T6, especially $\mathrm{T} 4+$ double aging treatment, can significantly improve the mechanical properties of the as-extruded tube. The microstructure reveals that the precipitation strengthening of the finely dispersed $\mathrm{MgZn}_{2}$ precipitates is the main reason for the strength increase. The fracture micromorphology of the as-extruded tube is mainly composed of dimples and cleavage facets, which is a typical ductile fracture. The fracture mode of the as-aged alloy tubes belongs to cleavage fracture. In addition, the electrochemical test results show the solution-treated ZM51 alloy tube has the best corrosion resistance. The improvement of corrosion resistance is mainly due to the microstructure uniformity and low phase volume fraction.
\end{abstract}

Keywords: extruded tube; heat treatment; mechanical properties; corrosion resistance

\section{Introduction}

Magnesium (Mg) alloys are the lightest metal structural material in current engineering applications, which can greatly reduce the weight of structural parts [1-4]. In addition, $\mathrm{Mg}$ alloys also have high specific strength and specific stiffness, good damping and shock absorption performance, so they are considered to be competitive materials for lightweight vehicles [2]. In recent years, cast $\mathrm{Mg}$ alloys have been widely used in automobiles, motorcycles and bicycles [5,6]. However, the further application of wrought $\mathrm{Mg}$ alloys is still limited due to the low strength and poor formability. Therefore, it is pressing to develop some new wrought $\mathrm{Mg}$ alloys with high strength and low cost. It is well known that pure Mg has low mechanical properties and cannot be used as an engineering structural material. Therefore, alloying and heat treatment are usually used to increase the strength [7].

$\mathrm{Mg}-\mathrm{Zn}$ series alloy is one of the most typical precipitation hardening Mg alloys [8-10]. When $\mathrm{Zn}$ content is about $6 \mathrm{wt.} \%$ (hereafter, all compositions are in weight percent unless stated otherwise), the alloy has a significant aging strengthening effect [11]. In addition, research [12] indicates that alloy with lower $\mathrm{Zn}$ content has better corrosion resistance than alloy with higher $\mathrm{Zn}$ content. When the $\mathrm{Zn}$ content exceeds the solid solubility limit, the corrosion performance is greatly reduced. The simple Mg- $\mathrm{Zn}$ 
binary alloys are rarely used in actual production due to the wide crystallization temperature range, poor fluidity, easy to produce micropores, hot tearing susceptibility, and poor corrosion resistance. Therefore, appropriate alloying elements must be added to the Mg-Zn binary alloys to improve their structure and properties. At present, the alloying elements added to $\mathrm{Mg}$-Zn binary alloys mainly include $\mathrm{Zr}, \mathrm{Mn}, \mathrm{Cu}$ and RE [13-15].

Mn [16] is an important alloying element in Mg alloys. Researchers [17-19] have found that Mn can remove Fe and other heavy metal elements in Mg alloys to avoid the formation of harmful intermetallic compounds. Therefore, the $\mathrm{Mn}$ addition improves corrosion resistance. Mn addition can also refine the grains, reduce the aging time, and improve creep resistance. In recent years, researchers have found that after adding a high content of $\mathrm{Mn}$ to $\mathrm{Mg}$ - $\mathrm{Zn}$ series alloys, the alloys can be subjected to a solution treatment at a higher temperature [20]. The $\alpha$-Mn particles precipitated during homogenization treatment will hinder the grain growth during the extrusion process. Moreover, the $\alpha$-Mn phases or the Mn-rich phases will become the nucleation cores of rod-like $\beta_{1}^{\prime}$ phases during aging treatment [20]. Kim [20] and our research group [21] have found that Mn addition can significantly enhance the precipitation strengthening effect and mechanical properties of $\mathrm{Mg}-6 \mathrm{Zn}$ series alloys. The micro-hardness of double-aged alloy increases from $77 \mathrm{HV}$ to $86 \mathrm{HV}$, and the yield strength (YS) and ultimate tensile strength (UTS) can increase from $213 \mathrm{MPa}$ and $312 \mathrm{MPa}$ to $340 \mathrm{MPa}$ and $366 \mathrm{MPa}$, respectively [22]. Based on this, a new type of Mg-6Zn-1Mn (ZM61) aging strengthened wrought $\mathrm{Mg}$ alloy has been developed. However, the ZM61 alloy is still not good in plasticity, and the elongation at fracture of the as-extruded and the double-aged alloys are only $11 \%$ and $6 \%$, respectively. Our research group previously studied the effect of Zn content (4-9\%) on the microstructure and mechanical properties of Mg-xZn-1Mn alloys [23,24]. Among them, when the $\mathrm{Zn}$ content is $5 \%$, the comprehensive mechanical properties are excellent, especially the plasticity is the best $[23,24]$. Until now, research on $\mathrm{Mg}-\mathrm{Zn}-\mathrm{Mn}$ series alloys have focused on hot compression in addition to adding alloying elements and heat treatment. Wu et al. [25] studied the dynamic precipitation behavior of ZM51 alloy before dynamic recrystallization during hot compression. The results indicated that the precipitation sequence during deformation for the alloy was more complex than the traditional aging process, and the deformation accelerates the precipitation and phase transition. At present, research on Mg-Zn-Mn series alloys are mainly focused on extruded bars and plates $[8,25,26]$. In practical applications, the use of as-extruded tubes is more extensive. However, the research on $\mathrm{Mg}-\mathrm{Zn}-\mathrm{Mn}$ series alloy tubes is rare. Therefore, Mg-5Zn-1Mn (ZM51) alloy tube is selected as the research object in the present study. The microstructure, mechanical properties, and electrochemical properties of the as-extruded ZM51 alloy tube under different heat treatment are studied, which can provide basic research for the popularization and application of the alloy system.

\section{Experiment}

The raw materials of the experimental alloy were pure $\mathrm{Mg}(\geq 99.9 \%)$, pure $\mathrm{Zn}(\geq 99.9 \%)$ and $\mathrm{Mg}-4.1 \% \mathrm{Mn}$ master alloy. The alloy ingot was prepared by the semi-continuous casting system of National Engineering Research Center for Magnesium Alloys in Chongqing University [27], and its size was $\varnothing 80 \mathrm{~mm} \times 200 \mathrm{~mm}$ after turning. The composition of the alloy ingot was measured by using the "area scanning" with an X-ray fluorescence spectrometer (XRF model-1800CCDE) (Shimadzu Company, Kyoto, Japan). The sample was a cylindrical shape with a diameter of $33 \mathrm{~mm}$, and polished to a metallurgical level before testing. The actual composition of the alloy is shown in Table 1. Overall, the actual contents of $\mathrm{Zn}$ and $\mathrm{Mn}$ elements meet the design requirements. In addition, the content of $\mathrm{Fe}$ and Ni impurity elements is lower than the standard (EN1753-1997 and GB/T 1177-2018) requirements. The ingot was homogenized at $330^{\circ} \mathrm{C}$ for $24 \mathrm{~h}$ followed by air cooling. Before extruding the ingot, both the alloy ingot and extrusion die were heated to $350^{\circ} \mathrm{C}$ for $60 \mathrm{~min}$. Then, the ingot was hot extruded into tubes under a controlled constant force with a ratio of $25: 1$ and a ram speed of $3 \mathrm{~m} / \mathrm{min}$ by a XJ-500 Horizontal Extrusion Machine (Wuxijishun Company, Jiangsu, China). The dimensions of the as-extruded tube are shown in Figure 1. After extrusion, the as-extruded tube was cooled in the 
open air. The as-extruded tube was solution-treated at $420^{\circ} \mathrm{C}$ for $2 \mathrm{~h}$ in air atmosphere, and then water cooling (T4). The following artificial aging treatments (T6) would be divided into single aging and double aging, respectively. The specific heat treatment process parameters are shown in Table 2.

Table 1. Chemical composition of the studied alloy.

\begin{tabular}{cccccc}
\hline \multirow{2}{*}{ Nominal Alloy } & \multicolumn{5}{c}{ Actual Composition (wt.\%) } \\
\cline { 2 - 6 } & $\mathbf{M g}$ & $\mathbf{Z n}$ & $\mathbf{M n}$ & $\mathbf{F e}$ & $\mathbf{N i}$ \\
\hline Mg-5Zn-1Mn & Bal. & 5.0346 & 1.0232 & 0.0028 & 0.0002 \\
\hline
\end{tabular}

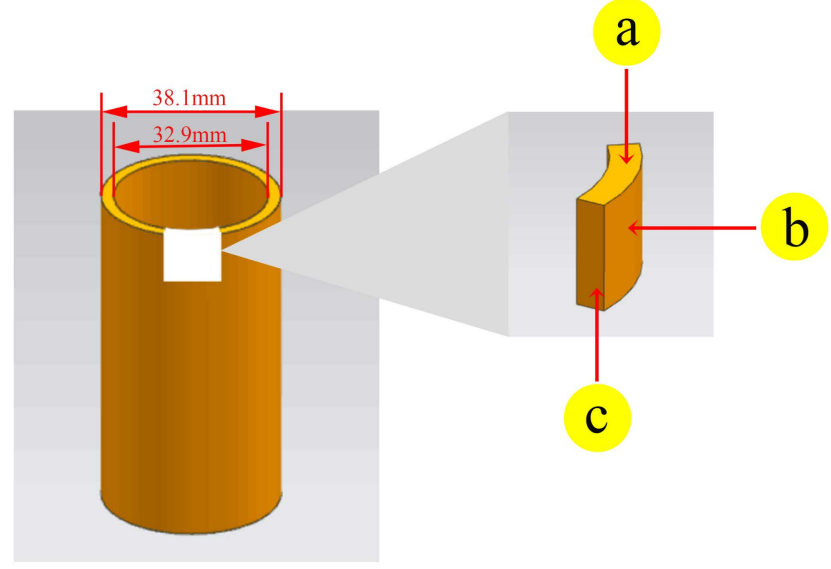

Figure 1. The ZM51 alloy tube size and sample diagram: (a) cross section, (b) outside surface and (c) longitudinal section.

Table 2. Heat treatment parameters for the ZM51 alloy tube.

\begin{tabular}{cc}
\hline Heat Treatment & Process Parameters \\
\hline Solution-treated (T4) & $420^{\circ} \mathrm{C} / 2 \mathrm{~h}+$ water cooling \\
T4 + single aging & $420{ }^{\circ} \mathrm{C} / 2 \mathrm{~h}+$ water cooling $+180^{\circ} \mathrm{C} / 16 \mathrm{~h}+$ air cooling \\
T4 + double aging & $420^{\circ} \mathrm{C} / 2 \mathrm{~h}+$ water cooling $+90^{\circ} \mathrm{C} / 24 \mathrm{~h}+$ air cooling $+1800^{\circ} \mathrm{C} / 16 \mathrm{~h}+$ air cooling \\
\hline
\end{tabular}

Mechanical properties tests of the as-extruded, solution-treated, and aged alloy tubes were performed at room temperature. The specimen was a full wall thickness longitudinal arc specimen, and the dimension is shown in Figure 2. The test was performed on an electrical universal material testing machine CMT-5105 (XinSanSi Enterprise Development Co., Ltd., Shanghai, China). Uniform unidirectional displacement stretching with the tensile strain rate of $3 \mathrm{~mm} / \mathrm{s}$ was used. To ensure the accuracy and repeatability of the experimental results, five tensile samples were tested for each state. From the stress-strain curve, the mechanical properties of the alloy tubes were determined, namely $0.2 \%$ yield strength (YS), ultimate tensile strength (UTS) and elongation at fracture (elongation).

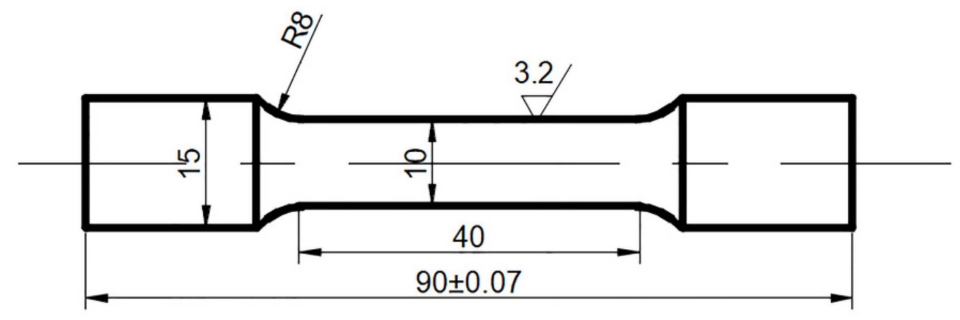

Figure 2. The schematic diagram of tensile sample.

As shown in Figure 1, the sample used for microstructure observation was a square specimen, and its side length was $10 \mathrm{~mm}$. The experimental samples were polished to a metallographic level 
and the polished samples were etched with a metallographic etchant. The metallographic etchant was prepared by mixing ethanol and acetic acid (at the ratio of 4.1:0.6), and appropriate amount of picric acid. The microstructure of etched samples was examined using an Olympus CF-LSM OLS4000 (Olympus Corporation, Tokyo, JP) and a TESCAN VEGA II scanning electron microscopy (SEM) (TESCAN Company, Brno, Czech) equipped with an Oxford INCA Energy 350 energy dispersive X-ray spectrometer (EDS) (Oxford Instruments Company, London, UK). Furthermore, the second phase distribution of the etched samples was observed and analyzed by a FEI Nova400 field emission scanning electron microscope (FE-SEM) (FEI Company, Hillsboro, GA, USA) and a FEI Tecnai G2 F20 transmission electrical microscope (TEM) (FEI Company, Hillsboro, GA, USA). Detail phase analysis was carried out using a D/MAX-2500PC X-ray diffractometer (XRD) (Rigaku Company, Tokyo, Japan). The experimental parameters were a scanning angle of $10^{\circ}$ to $90^{\circ}$ and a scanning speed of $4^{\circ} / \mathrm{min}$. In addition, the corrosion resistance was tested on a CHI660C (CH Instruments Inc., Shanghai, China) electrochemical workstation using a three electrode. The three electrodes are a working electrode (sample with an exposed area of $0.5 \mathrm{~cm}^{2}$ ), a reference electrode (saturated calomel electrode), and an auxiliary electrode (platinum electrode). The electrolyte was $3.5 \mathrm{~g} / \mathrm{L} \mathrm{NaCl}$ solution, and the scanning speed was set to $5 \mathrm{mV} / \mathrm{s}$. The corrosion polarization curves obtained were fitted by CHI660C software to analyze the electrochemical corrosion performance.

\section{Results and Discussions.}

\subsection{As-Cast and AsHhomogenized Microstructures}

Figure 3a shows the optical microstructure (OM) image of the as-cast ZM51 alloy. It can be clearly observed that there are many coarse $\alpha-\mathrm{Mg}$, and there are network intermetallic compounds between the dendritic crystals. Moreover, the dendrite crystals are black in the center and gray in the periphery, which is caused by interdendritic segregation. The results show the interdendritic compound is $\mathrm{Mg}_{7} \mathrm{Zn}_{3}$ phase by SEM and XRD analysis. To eliminate the interdendritic segregation of the as-cast ZM51 alloy, it is necessary to perform a homogenization treatment. The OM image of the as-homogenized ZM51 alloy is shown in Figure 3b. It can be seen that the coarse dendrite disappears and the intergranular $\mathrm{Mg}_{7} \mathrm{Zn}_{3}$ phase is also partially dissolved. To further determine the second phase composition of the as-homogenized ZM51 alloy, the microstructure of the alloy is analyzed by SEM (Figure 4b) and EDS (Figure 4d). The results show that most of $\mathrm{Mg}_{7} \mathrm{Zn}_{3}$ phase is dissolved in the $\mathrm{Mg}$ matrix, and there is still a small part of the residual $\mathrm{Mg}_{7} \mathrm{Zn}_{3}$ phase. The fine particles existing around the $\mathrm{Mg}_{7} \mathrm{Zn}_{3}$ phase can be further observed by the high angle annular dark field scanning TEM (HADDF-STEM) (Figure 5). It can be identified as $\mathrm{MgZn}_{2}$ phase by combining with XRD patterns (Figure 6) [26]. In addition, the line scan (Figure 4b) shows that Mn is evenly distributed in the alloy.

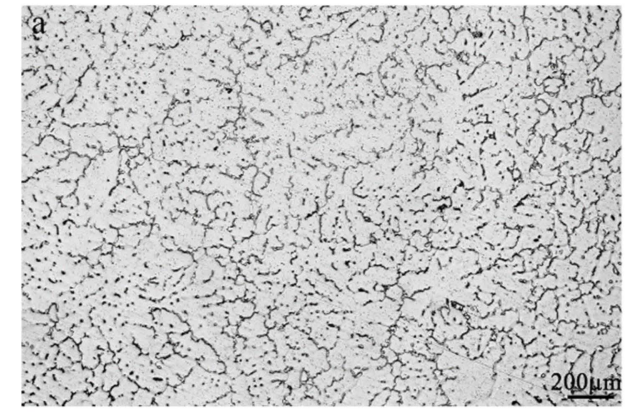

(a)

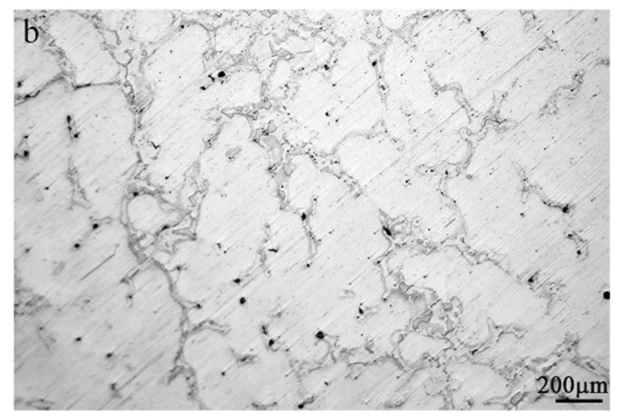

(b)

Figure 3. Optical images of the (a) as-cast and (b) as-homogenized ZM51 alloys. 

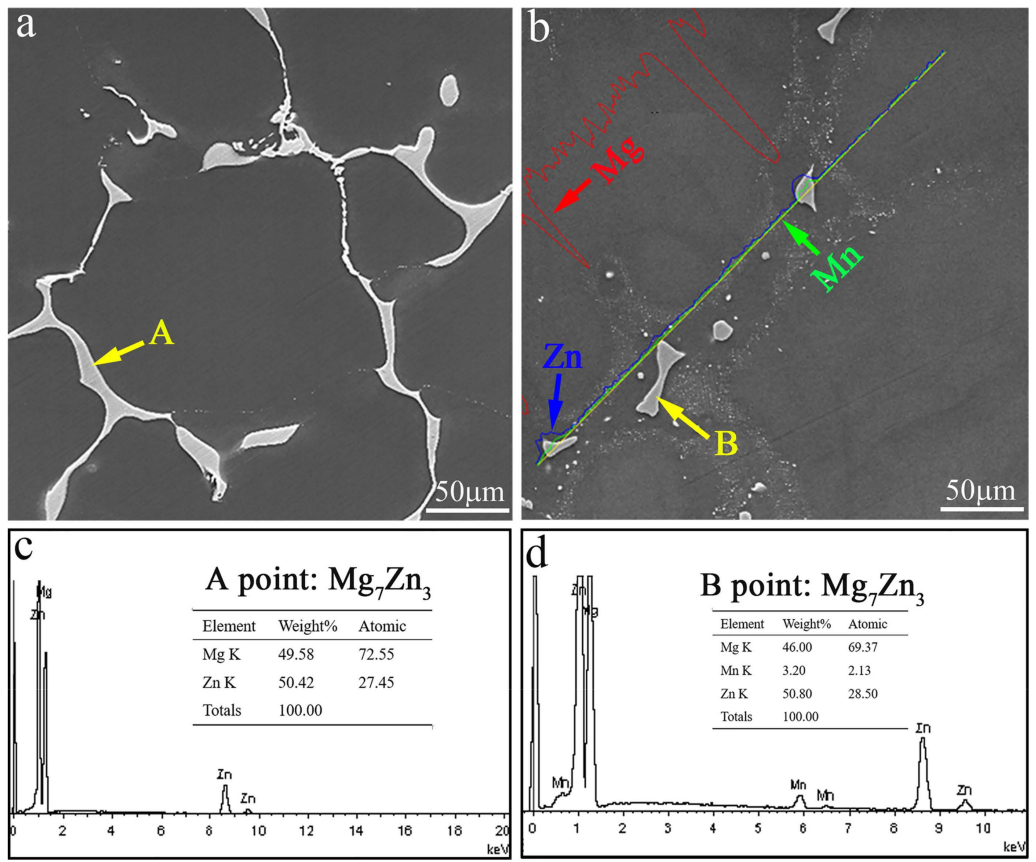

Figure 4. SEM (scanning electron microscopy) images of the (a) as-cast and (b) as-homogenized ZM51 alloys, and (c,d) corresponding EDS (energy dispersive X-ray spectrometer) results of the points in $(\mathbf{a}, \mathbf{b})$.

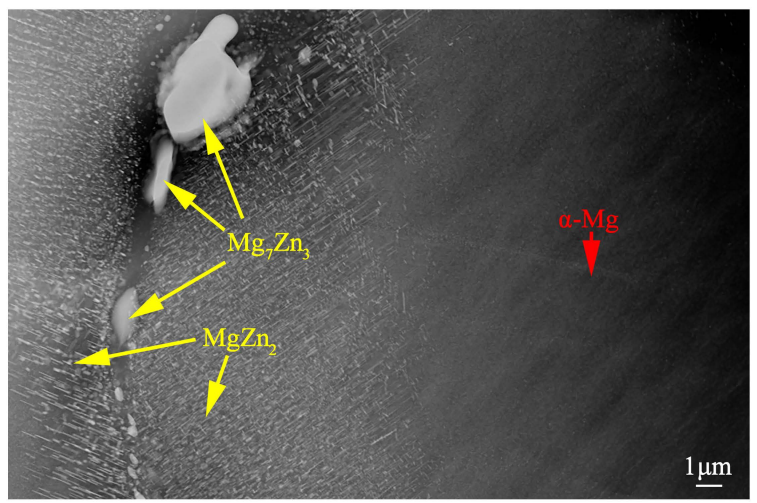

Figure 5. HADDF-STEM (high-angle annular dark-field scanning transmission electron microscope) image of the as-homogenized ZM51 alloy.

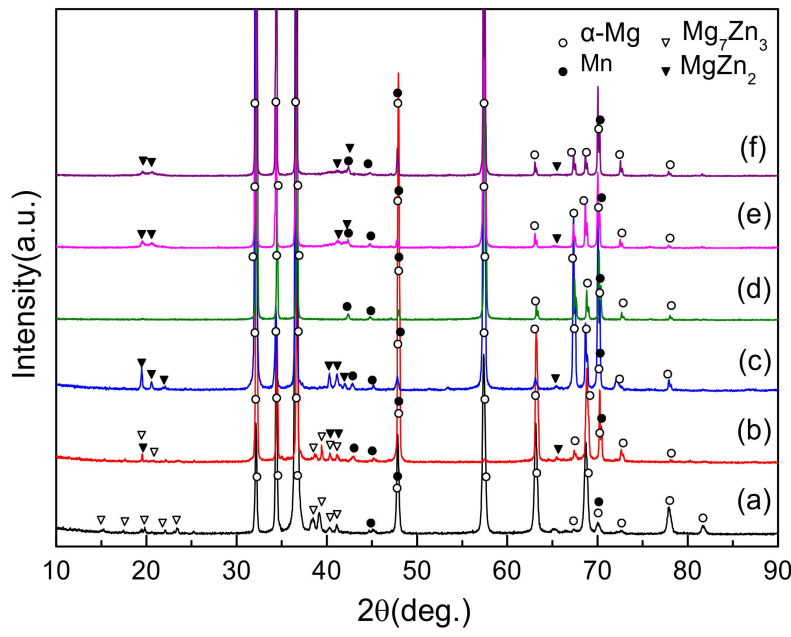

Figure 6. XRD (X-ray diffractometer) patterns of the ZM51 alloy under different conditions: (a) as-cast, (b) as-homogenized, (c) as-extruded, (d) T4, (e) T4+single-aged and (f) T4+double-aged. 


\subsection{As-Extruded and Solution-Treated Microstructures}

Figure 7 shows the OM and SEM images of the as-extruded ZM51 alloy tube. It is found that complete dynamic recrystallization occurs during the extrusion process. The as-extruded microstructures are mainly composed of small equiaxed recrystallized grains, with the average grain size of $13.6 \pm 2 \mu \mathrm{m}$. There is a small amount of unrecrystallized deformed grains, and extrusion stringers exist along the extrusion direction (ED). During the extrusion process, the residual intermetallic compounds are broken in parts under three-way compression stress and distribute along the ED. Comparing the three observation directions, it is found that the structure and grain size are similar. During the hot extrusion, the precipitates pin the dislocations, sub-grain boundaries, and dynamic recrystallized grain boundaries, which hinders the nucleation and growth of dynamic recrystallized grains [25]. Therefore, the alloy grains are relatively small after extrusion.
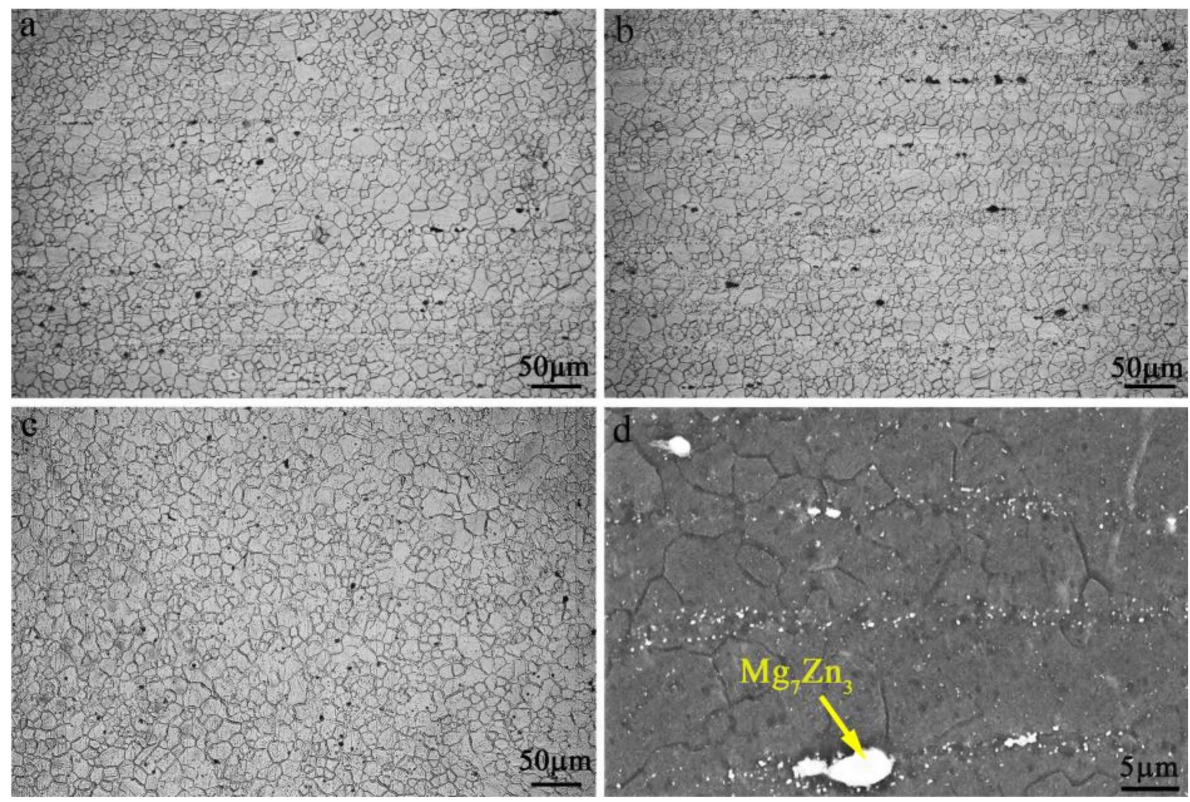

Figure 7. Optical images of the (a) longitudinal section, (b) outside surface and (c) cross section for the as-extruded ZM51 alloy tube, and (d) SEM image of the outside surface of the as-extruded ZM51 alloy tube.

Figure 8a-c show the OM images of the solution-treated ZM51 tube. It can be seen that the grain growth of the extruded ZM51 alloy is very obvious after solution treatment The extrusion stringers originally existing between the grains disappear, and almost all secondary phase particles are dissolved in the Mg matrix. Detailed microstructures of the solution-treated ZM51 alloy are revealed in the backscattered electron (BSE) micrographs (Figure 8d). The results show that the Zn-rich phases almost disappear, and very little residual particles are inevitable in the microstructure. It shows that the ZM51 alloy has a very good solid solution effect after heating at $420^{\circ} \mathrm{C}$ for $2 \mathrm{~h}$. Figure 9 shows the TEM images of the solution-treated ZM51 alloy tube. Only $\alpha$-Mn phases can be observed in the figure. Most of $\alpha$-Mn phases are spherical or polygonal, and a few are rod-like, with sizes ranges from tens to hundreds of nanometers. The melting point of $\alpha-\mathrm{Mn}$ is relatively high, and its distribution in the $\mathrm{Mg}$ matrix is relatively dispersed (Figure 9a), so it can play a role of dispersion strengthening to a certain extent [21]. 

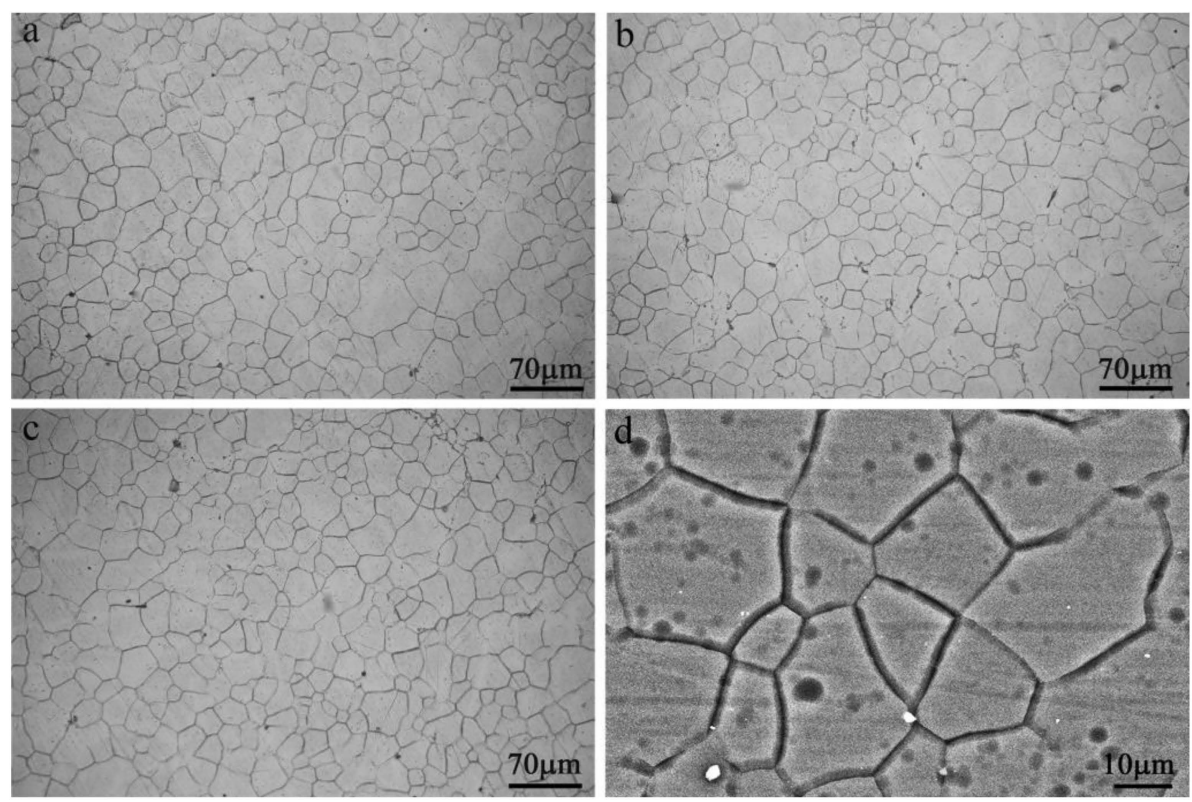

Figure 8. Optical images of the (a) longitudinal section, (b) outside surface and (c) cross section for the solution-treated ZM51 alloy tube, and (d) BSE-SEM image of the outside surface of the solution-treated ZM51 alloy tube.
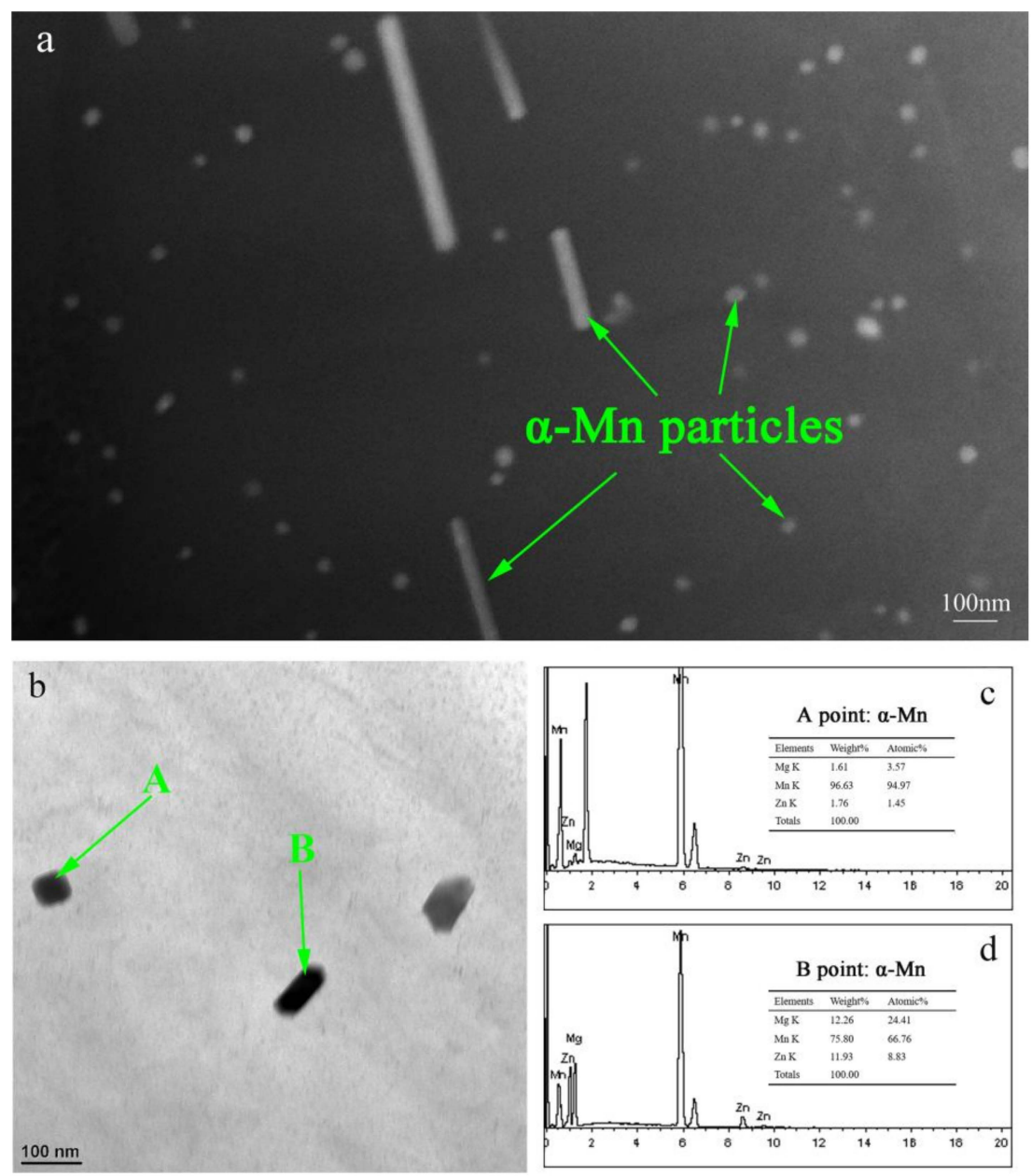

Figure 9. (a)HAADF-STEM and (b)Bright-TEM (transmission electrical microscope) images of the solution-treated ZM51 alloy tube, and (c,d) corresponding EDS results of the points indicated in (b). 


\subsection{As-Aged Microstructures}

Most of the single-phase supersaturated solid solutions obtained by the solution treatment are metastable. If kept at a certain temperature for a period of time, new phase precipitation, and transformation will occur in the matrix. Therefore, the strength and hardness of the alloy are significantly improved. Figure 10 shows the OM and SEM images of the single-aged ZM51 alloy. The results show that the average grain size of the aged alloy is $20.8 \pm 2 \mu \mathrm{m}$, which is no significant change compared to the solution-treated alloy. The reason is that the diffusion capacity of the $\mathrm{Mg}$ atoms is extremely low at this aging temperature $\left(180^{\circ} \mathrm{C}\right)$, and there is not enough energy to achieve the grain boundary expansion [28]. In addtion, there is also no significant difference between the single-aged and double-aged alloys from metallographic and low magnification SEM. Figure 6e and $\mathrm{f}$ show the XRD results of the aged ZM51 alloys. Except for the $\alpha-\mathrm{Mg}$ and $\alpha-\mathrm{Mn}$ phases, the $\mathrm{MgZn}_{2}$ phase can be observed. As mentioned previously, almost all the Mg-Zn phases dissolve in the $\mathrm{Mg}$ matrix after solution treatment. It can be concluded that the $\mathrm{MgZn}_{2}$ phase formed during aging treatment is a finely precipitated phase.
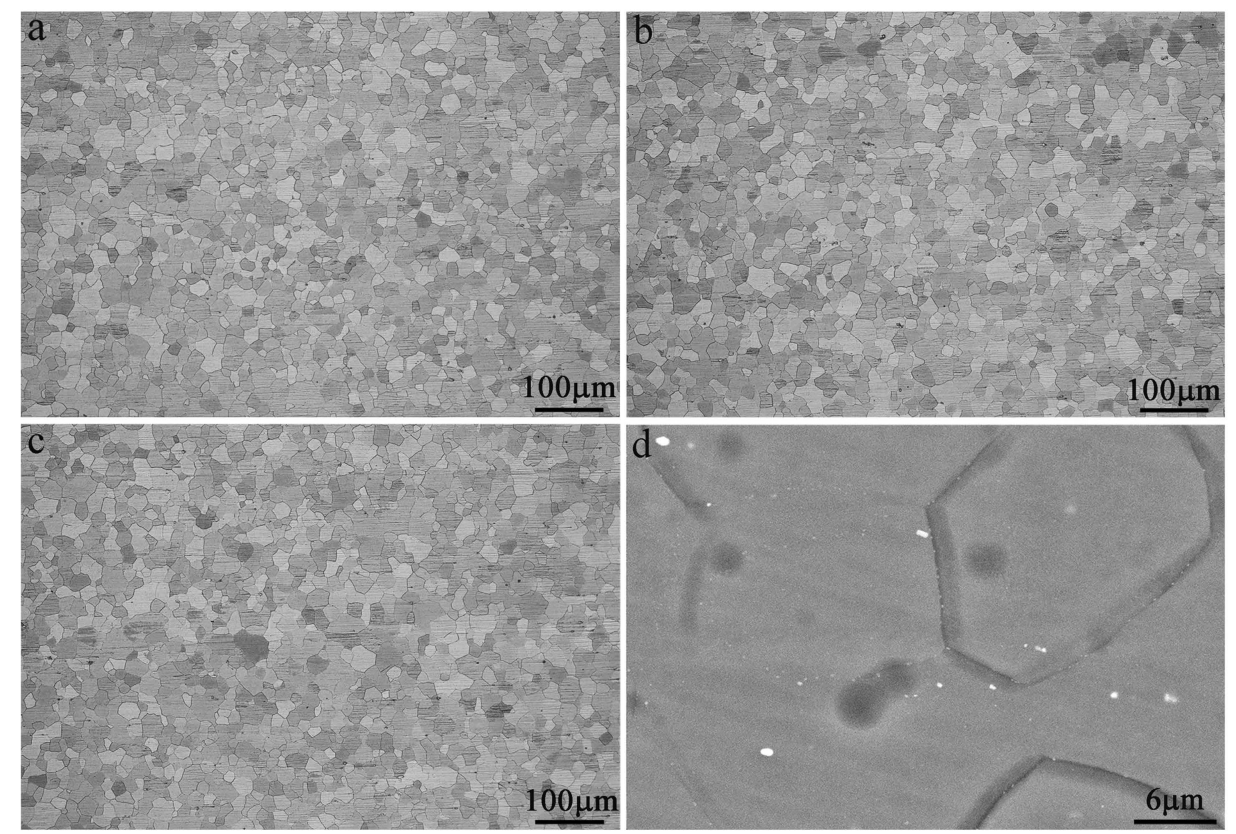

Figure 10. Optical images of the (a) longitudinal section, (b) outside surface and (c) cross section of the single-aged ZM51 alloy, and (d) SEM image of the outer surface of the single-aged ZM51 alloy.

A high-resolution SEM is used to further observe the precipitated phase. Figure 11 shows the high-resolution SEM images of the T4 + single-aged and T4 + double-aged ZM51 alloys. It can be found that the microstructures of the two are basically similar, except that the precipitates of the latter are more dispersed. After T4 + single aging and T4 + double aging treatments, the phase density of $\mathrm{MgZn}_{2}$ is about $48 \pm 7$ particles $/ \mu \mathrm{m}^{2}$ and $63 \pm 8$ particles $/ \mu \mathrm{m}^{2}$, respectively. The purpose of the lower temperature pre-aging treatment in double aging process is to first generate many fine G.P. zones in the matrix. The G.P. zones can serve as a heterogeneous nucleation core of the $\beta^{\prime}{ }_{1}$ rod-like phase in the second-stage aging. This can reduce the nucleation energy barrier of the rod-like phase and maintain a high precipitation rate $[23,24]$. Therefore, the precipitates after double aging are more dispersed. The morphology and orientation relationship of precipitates are further studied by TEM (Figure 12). According to the literature $[29,30], \beta_{1}^{\prime}$ is a rod-like phase perpendicular to $(0001)_{\alpha-\mathrm{Mg}}$, and $\beta_{2}{ }_{2}$ is a disc-like phase parallel to $(0001)_{\alpha-M g}$. Two different shapes of $\beta_{1}^{\prime}$ can be seen in the TEM image. The single ones are thin or slender, while the others grown on $\mathrm{Mn}$ are relatively coarse. When $\alpha-\mathrm{Mn}$ is used as a heterogeneous nucleation core of the $\mathrm{MgZn}$ 2 phase, it has a lower nucleation energy 
barrier. Therefore, these rod-like phases are more likely to nucleate and precipitate earlier, resulting in them having sufficient growth time.
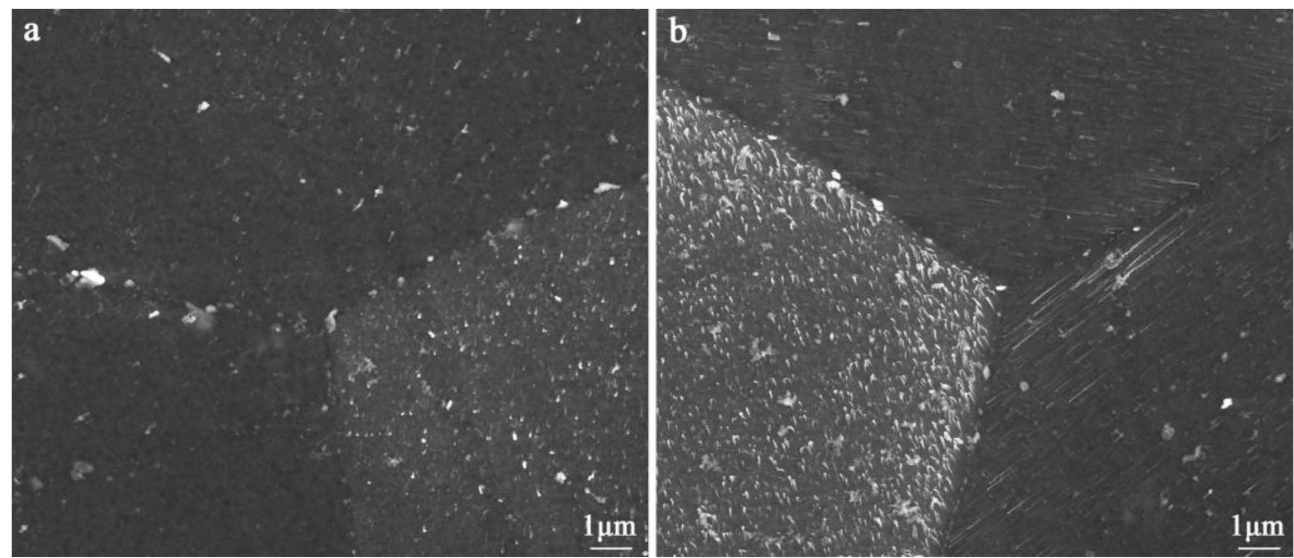

Figure 11. High-resolution SEM images of the outer surface of the (a) single-aged and (b) double-aged ZM51 alloys.

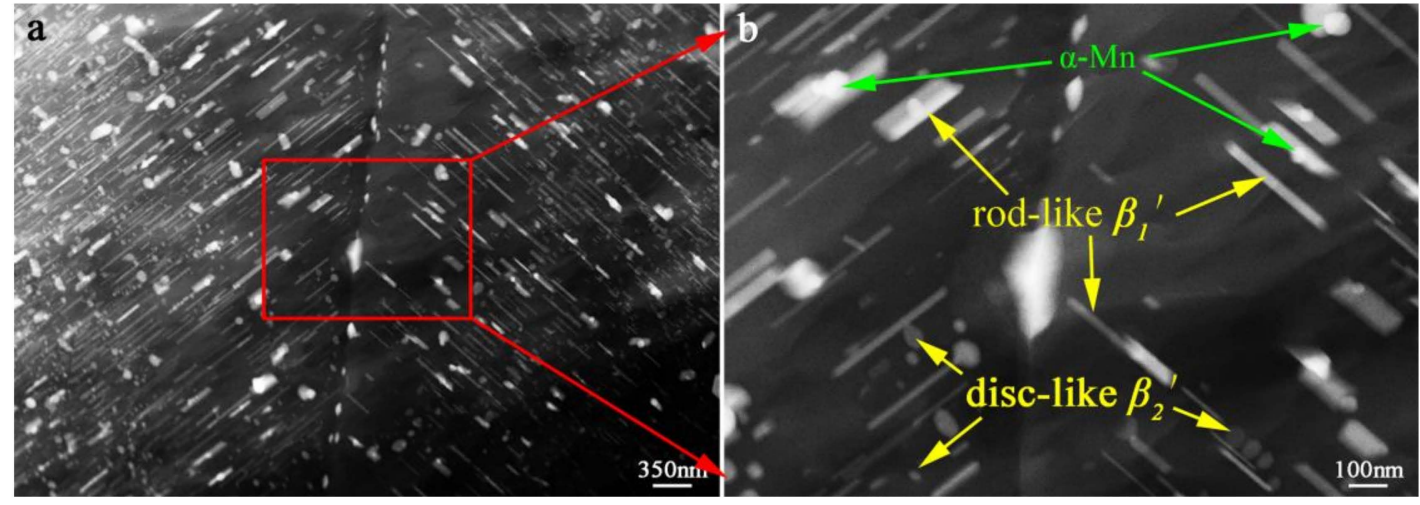

Figure 12. (a) HADDF-STEM image of the double-aged ZM51 alloy, (b) the enlargement of the rectangular part in the circle in (a).

\subsection{Mechanical Properties}

Figure 13 shows the mechanical properties of the as-extruded ZM51 alloy tube under different heat treatment conditions. The results show that the as-extruded ZM51 alloy tube has an excellent elongation of $21.4 \%$, which is the most prominent highlight in mechanical properties. After T4 treatment, the grains of the as-extruded alloy tube generally grow, which weakens the fine grain strengthening effect. Therefore, the strength and elongation of the as-extruded ZM51 alloy tube decrease after T4 treatment. In addition, many $\mathrm{Mg}-\mathrm{Zn}$ particles are dissolved in the $\mathrm{Mg}$ matrix, which can further reduce the strength. After T4 + single aging and T4 + double aging treatment, the elongation of the as-extruded alloy decreases significantly from $21.4 \%$ to $11.6 \%$ and $8.4 \%$. On the contrary, the YS and UTS have been greatly improved. After T4 + single aging treatment, the YS gradually increases from $180 \mathrm{MPa}$ in the as-extruded condition to $219 \mathrm{MPa}$, and the UTS also increases from $286 \mathrm{MPa}$ to $315 \mathrm{MPa}$. After $\mathrm{T} 4$ + double aging treatment, the YS and UTS increase to $297 \mathrm{MPa}$ and $349 \mathrm{MPa}$, respectively. It can be known from the above that the grain size of the as-aged ZM51 alloy tubes is much larger than that of the extruded state, but the strength does not decrease correspondingly. This indicates that the reason for the significant increase in strength is not the fine grain strengthening. This is mainly due to the precipitation of fine and dispersed $\mathrm{MgZn}_{2}$ during aging process, which hinders the dislocation movement during plastic deformation. 


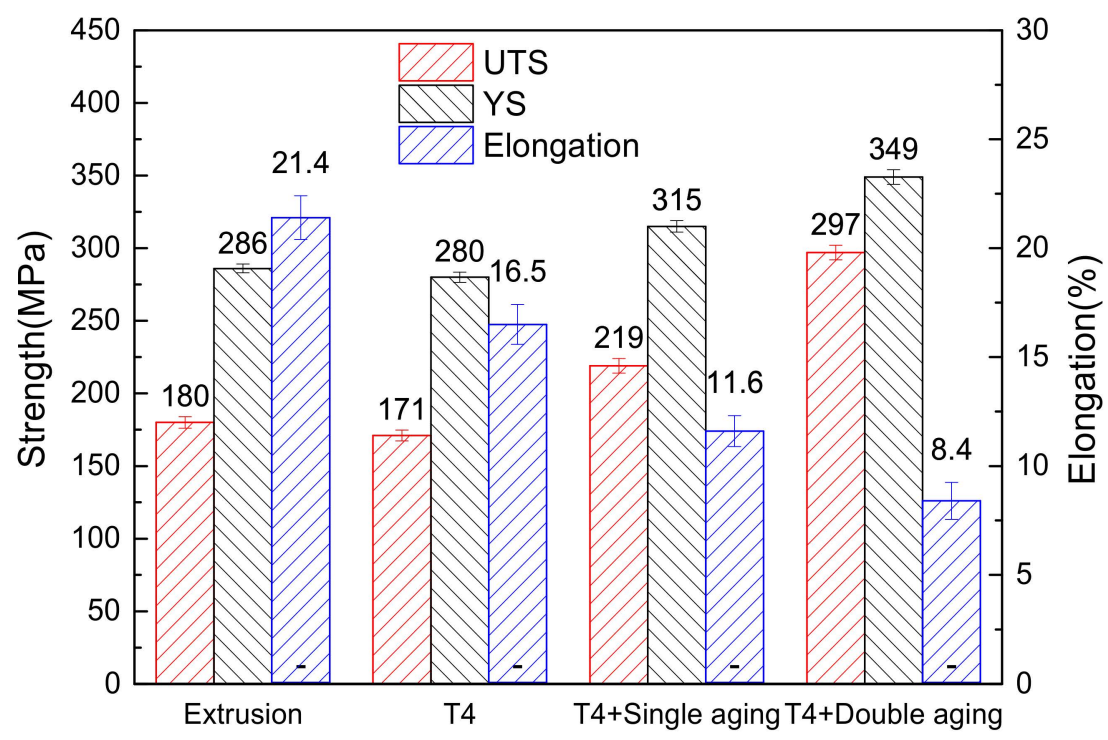

Figure 13. The mechanical properties of the ZM51 alloys in as-extruded, T4, single-aged, and double-aged conditions.

\subsection{Fracture Mode and Fracture Analysis}

Figure 14 shows the fracture SEM images of the as-extruded, T4 + single-aged and T4 + double-aged ZM51 alloy tubes. The results show that the fracture modes of ZM51 alloy tubes are obviously different under different conditions. As shown in Figure 14a, the as-extruded ZM51 alloy tube has a large number of dimples with different depths on the fracture surface, so its fracture is regarded as ductile fracture. Deep dimples distribute around the cleavage steps, while shallow dimples gather together. The existence of a large number of dimples can not only reduce the local stress concentration, but also hinder the crack extension [31]. This also supports why the as-extruded ZM51 alloy tube has an excellent plasticity. In Figure 14c, there are almost no dimples, mainly blocky cleavage facets and tear ridges. The entire fracture is composed of a large number of cleavage steps connected to the cleavage facets. Therefore, the fracture of the ZM51 alloy tube is a typical cleavage fracture after T4 + double aging treatment [32]. At the same time, it also supports why its plasticity decreases and strength increases from the reverse side. Figure $14 \mathrm{~b}$ is the fracture SEM image of the T4 + single-aged ZM51 alloy tube. Comparing Figure 14a, the number of dimples reduces, so the plasticity reduces. However, the increase of blocky cleavage facets indicates that its strength increases. In summary, the fracture of the T4 + single-aged ZM51 alloy tube is a transition from ductile fracture to cleavage fracture, so its mechanical properties are between the as-extruded and T4 + double-aged ZM51 alloys.
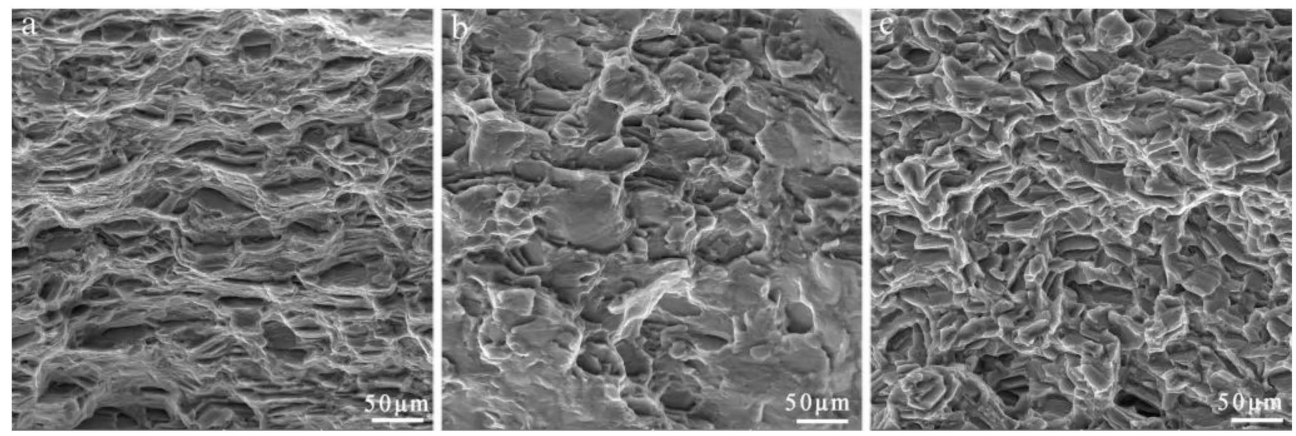

Figure 14. SEM images of fracture surface of the (a) as-extruded, (b) T4 + single-aged and (c) T4 + double-aged ZM51 alloys. 


\subsection{Electrochemical Tests}

The widespread use of $\mathrm{Mg}$ alloys is limited by their susceptibility to corrosion, especially in aggressive environments (sea spray) or aqueous solutions [33]. Figure 15 shows the potentio-dynamic polarization curves of the as-extruded ZM51 alloy tube under different heat treatment conditions. Table 3 shows the polarization parameters ( $\mathrm{E}_{\mathrm{corr}}$ and $\mathrm{I}_{\mathrm{corr}}$ ) calculated from the Tafel extrapolation of the potentio-dynamic polarization curves. The corrosion current reflects the corrosion rate. The larger the value, the faster the alloy corrodes [34]. It can be seen that the corrosion current of the as-extruded ZM51 alloy is the largest. During the corrosion process, the surface of the ZM51 alloy is divided into micro anode regions and micro cathode regions. The previous microstructure analysis shows that there are more Mg-Zn phases in the as-extruded ZM51 alloy. Therefore, the Mg-Zn phases are regarded as micro cathode regions due to the higher electrode potential, and $\mathrm{Mg}$ matrix is regarded as micro anode regions [35]. Due to the large volume fraction and discontinuous distribution of $\mathrm{Mg}-\mathrm{Zn}$ intermediate compounds, there are more galvanic couples $(\mathrm{Mg}-\mathrm{Zn} / / \alpha-\mathrm{Mg})$ formed in the as-extruded ZM51 alloy tube, which causes severe corrosion [36].

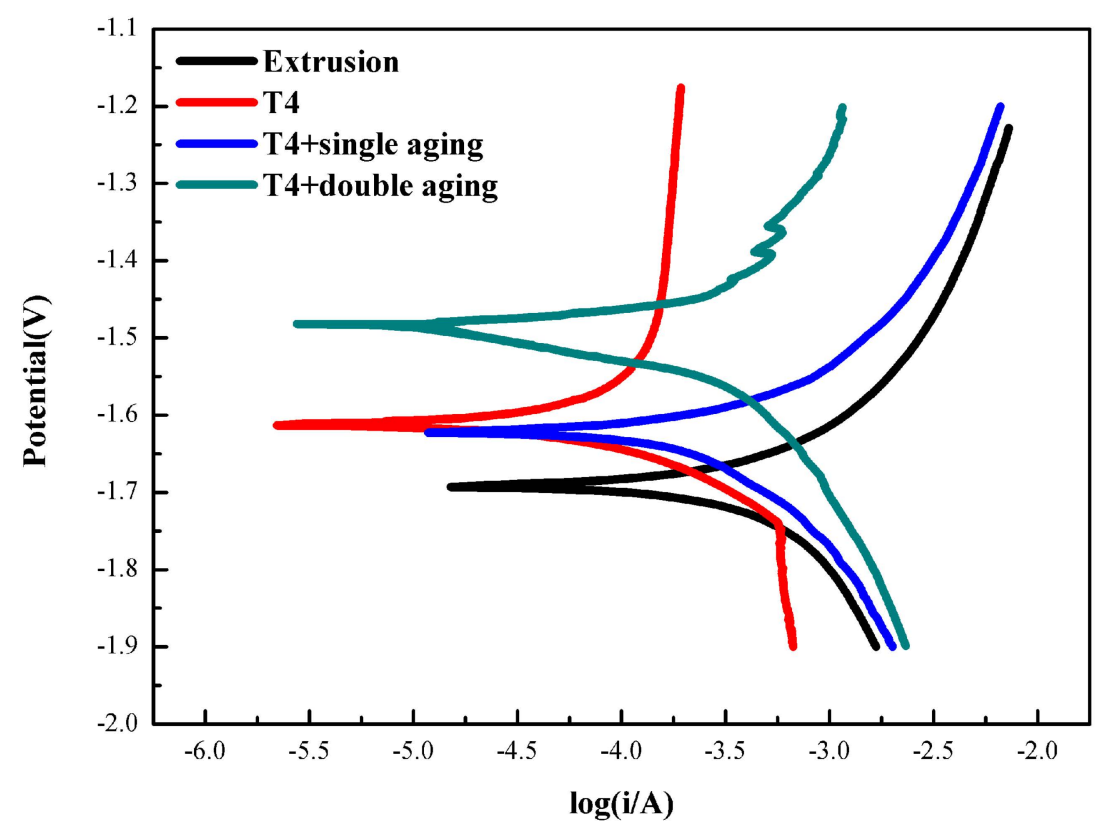

Figure 15. Polarization curves of the ZM51 alloys in different heat treatment conditions.

Table 3. Fitting results of polarization curves for the ZM51 alloys in different conditions.

\begin{tabular}{ccc}
\hline Alloy States & $\mathbf{E}_{\text {corr }}(\mathbf{V})$ & $\mathbf{I}_{\text {corr }}(\mathbf{A})$ \\
\hline As-extruded & -1.6938 & $5.642 \times 10^{-4}$ \\
T4 & -1.5692 & $1.028 \times 10^{-4}$ \\
T4 + single-aged & -1.6229 & $2.408 \times 10^{-4}$ \\
T4 + double-aged & -1.4759 & $2.331 \times 10^{-4}$ \\
\hline
\end{tabular}

After T4 treatment, almost all Mg-Zn phases are dissolved in the Mg matrix by, which greatly reduce the micro-galvanic corrosion effect. Therefore, the corrosion current of the solution-treated ZM51 alloy is the smallest. Research [37] indicates that grain boundaries can reduce the current intensity the grain interior and the grain boundaries or generating a more compact passivation film. That is to say, the grain refinement can improve the corrosion resistance to a certain extent. Although the grain growth caused by $\mathrm{T} 4$ has a negative impact on the corrosion resistance, the reduction of micro-galvanic corrosion is the main reason affecting the corrosion resistance of the solution-treated ZM51 alloy. In addition, the second phase particles precipitated by T4 + double aging are more uniform 
than T4 + single aging. The research results [38,39] show that the fine and uniformly distributed second phases make the alloy tend to uniform corrosion, which is beneficial to improve the corrosion resistance of the alloy. Therefore, it can be preliminarily explained that the corrosion resistance of the T4 + double-aged ZM51 alloy is better than the T4 + single-aged ZM51 alloy. In general, hot extrusion directly affects the grain size and microstructure of ZM51 alloy tube. Heat treatment after hot extrusion will affects the aging precipitation behavior. These will directly affect the corrosion resistance of the tube $[40,41]$. Therefore, in order to further understand the influencing factors of corrosion behavior, future work is needed to systematically study the influence of microstructure on corrosion behavior of the ZM51 alloy tube.

\section{Summary}

The as-extruded ZM51 alloy tube has undergone complete dynamic recrystallization and has a good elongation, up to $21.4 \%$. After T4 and artificial aging treatments, the finely dispersed $\mathrm{MgZn}_{2}$ phases begin to precipitate in the grains, which greatly improves the strength of the ZM51 alloy tube. Among them, the YS and UTS of the double-aged alloy tube are $297 \mathrm{MPa}$ and $349 \mathrm{MPa}$, which are $65 \%$ and $22 \%$ higher than the as-extruded state, respectively. In addition, the results of the polarization curve indicate that the ZM51 alloy tube in the as-extruded condition has the worst corrosion resistance. After T4 treatment, the corrosion resistance of the ZM51 alloy tube increases significantly, and its corrosion potential and corrosion current are $-1.5692 \mathrm{~V}$ and $1.028 \times 10^{-4} \mathrm{~A}$. The corrosion current of the ZM51 alloy tubes after T6 treatments is more than twice that of T4, indicating the corrosion resistance after T6 treatments is reduced. The next step is to study the relationship between corrosion behavior and microstructure in detail.

In general, heat treatment has a significant impact on the mechanical properties and corrosion resistance of ZM51 alloy tube, making it a tube with great potential for development. To realize the application of ZM51 tube, its welding is also a very important factor. However, $\mathrm{Zn}$ is known as an element that increases the hot tearing susceptibility of $\mathrm{Mg}$ alloy during casting or welding. This makes it difficult to weld Mg-Zn-Mn series alloys by conventional welding methods. Therefore, a lot of research related to welding should be performed to popularize the $\mathrm{Mg}-\mathrm{Zn}-\mathrm{Mn}$ series alloys. Moreover, the texture orientation is bound to be closely related to the mechanical properties of ZM51 tube as well, and relevant research should also be carried out in future work.

Author Contributions: L.L. and H.C. equally contributed to this work. Conceptualization, L.L., H.C., F.Q. and Q.W.; methodology, L.L., H.C. and F.Q.; data curation, L.L.; writing-original draft preparation, L.L.; writing-review and editing, L.L., X.Y. and F.Q.; supervision, F.Q., N.Z., Y.L. and X.O. All authors have read and agreed to the published the final manuscript.

Funding: This work was supported by National Natural Science Foundation of China (51701172), China Postdoctoral Science Foundation (2018M632977), Natural Science Foundation of Hunan Province (2018JJ3504), Educational Commission of Hunan Province of China (16C1527), Foundation of Xiangtan University (KZ08034) and Natural Science Foundation of Xiangtan University (KZ03014).

Conflicts of Interest: The authors declare no conflict of interest.

\section{References}

1. Lorimer, G.W.; Robson, J. Review on research and development of Magnesium alloys. Acta Metall. Sin. 2008, 21, 313-328. [CrossRef]

2. Xu, T.; Yang, Y.; Peng, X.; Song, J.; Pan, F. Overview of advancement and development trend on magnesium alloy. J. Magnes. Alloy 2019, 7, 536-544. [CrossRef]

3. Yang, Q.S.; Jiang, B.; Pan, H.C.; Song, B.; Jiang, Z.T.; Dai, J.H.; Wang, L.F.; Pan, F.S. Influence of different extrusion processes on mechanical properties of magnesium alloy. J. Magnes. Alloy 2014, 2, $220-224$. [CrossRef]

4. Joost, W.J.; Krajewski, P.E. Towards magnesium alloys for high-volume automotive applications. Scripta Mater. 2017, 128, 107-112. [CrossRef] 
5. Mehta, D.S.; Masood, S.H.; Song, W.Q. Investigation of wear properties of magnesium and aluminum alloys for automotive applications. J. Mater. Process. Tech. 2004, 155, 1526-1531. [CrossRef]

6. Hirsch, J.; Al-Samman, T. Superior light metals by texture engineering: Optimized aluminum and magnesium alloys for automotive applications. Acta Mater. 2013, 61, 818-843. [CrossRef]

7. Silva, E.P.D.; Buzolin, R.H.; Callegari, B.; Warchomicka, F.; Requena, G.C.; Pinto, H.C. Effect of Mischmetal Additions and Solution Heat Treatments (T4) on the Microstructure and Mechanical Properties of Thixocast ZK60-RE Magnesium Alloys. Mater. Sci. Forum 2016, 879, 2300-2305. [CrossRef]

8. Jiang, J.M.; Wu, J.; Ni, S.; Yan, H.; Song, M. Improving the mechanical properties of a ZM61 magnesium alloy by pre-rolling and high strain rate rolling. Mater. Sci. Eng. A 2018, 712, 478-484. [CrossRef]

9. Somekawa, H.; Singh, A.; Mukai, T. Microstructure evolution of Mg-Zn binary alloy during a direct extrusion process. Scripta Mater. 2009, 60, 411-414. [CrossRef]

10. Li, J.H.; Barrirero, J.; Sha, G.; Aboulfadl, H.; Mücklich, F.; Schumacher, P. Precipitation hardening of an Mg-5Zn-2Gd-0.4Zr (wt. \%) alloy. Acta Mater. 2016, 108, 207-218. [CrossRef]

11. Zhong, L.; Wang, Y.; Dou, Y. On the improved tensile strength and ductility of Mg-Sn-Zn-Mn alloy processed by aging prior to extrusion. J. Magnes. Alloy 2019, 7, 637-647. [CrossRef]

12. Němec, M.; Jäger, A.; Tesař, K.; Gärtnerová, V. Influence of alloying element Zn on the microstructural, mechanical and corrosion properties of binary $\mathrm{Mg}-\mathrm{Zn}$ alloys after severe plastic deformation. Mater. Charact. 2017, 134, 69-75. [CrossRef]

13. Yun, B.; Fang, C.F.; Hai, H.; Qi, G.H.; Zhang, X.G. Effects of yttrium on microstructure and mechanical properties of Mg-Zn-Cu-Zr alloys. T. Nonferr. Metal Soc. 2010, 20, 357-360. [CrossRef]

14. Wang, Q.D.; Li, D.Q.; Li, Q.; Ding, W.J. Effects of Er on microstructure and mechanical properties of Mg-Zn-Er-Zr magnesium alloys. Mater. Sci. Forum 2007, 546, 105-108. [CrossRef]

15. You, S.; Huang, Y.; Kainer, K.U.; Hort, N. Recent research and developments on wrought magnesium alloys. J. Magnes. Alloy 2017, 5, 239-253. [CrossRef]

16. She, J.; Pan, F.S.; Guo, W.; Tang, A.T.; Gao, Z.Y.; Luo, S.Q.; Song, K.; Yu, Z.W.; Rashad, M. Effect of high Mn content on development of ultra-fine grain extruded magnesium alloy. Mater. Design 2016, 90, 7-12. [CrossRef]

17. Hou, C.; Qi, F.; Ye, Z.; Zhao, N.; Zhang, D.; Ouyang, X. Effects of Mn addition on the microstructure and mechanical properties of Mg-Zn-Sn alloys. Mater. Sci. Eng. A 2020, 774, 138933. [CrossRef]

18. Xu, C.; Nakata, T.; Fan, G.H.; Li, X.W.; Tang, G.Z.; Kamado, S. Enhancing strength and creep resistance of Mg-Gd-Y-Zn-Zr alloy by substituting Mn for Zr. J. Magnes. Alloy 2019, 7, 388-399. [CrossRef]

19. Huang, D.; Liu, S.; Xu, H.; Du, Y. Phase equilibria of the Mg-Mn-Zn system at 593K (320 $\left.{ }^{\circ} \mathrm{C}\right)$. J. Alloy. Compd. 2016, 688, 1115-1124. [CrossRef]

20. Park, S.S.; Oh, Y.S.; Kang, D.H.; Kim, N.J. Microstructural evolution in twin-roll strip cast Mg-Zn-Mn-Al alloy. Mater. Sci. Eng. A 2007, 449, 352-355. [CrossRef]

21. Zhang, D.F.; Qi, F.G.; Shi, G.L.; Dai, Q.W. Effects of Mn Content on Microstructure and Mechanical Properties of Mg-Zn-Mn Wrought Alloys. Rare Metal Mat. Eng. 2010, 39, 2205-2210. [CrossRef]

22. Dai, Q.W.; Zhang, D.F.; Yuan, W.; Shi, G.L.; Duan, H.L. Researches on extrusion, microstructure and mechanical properties of new Mg-Zn-Mn alloy. J. Mater. Eng. 2008, 4, 38-42. [CrossRef]

23. Zhang, D.F.; Shi, G.L.; Zhao, X.B.; Qi, F.G. Microstructure evolution and mechanical properties of $\mathrm{Mg}-\% \mathrm{Zn}-1 \% \mathrm{Mn}(=4,5,6,7,8,9)$ wrought magnesium alloys. T. Nonferr. Metal. Soc. China 2011, 21, 15-25. [CrossRef]

24. Zhang, D.F.; Zhao, X.B.; Shi, G.L. Effects of Zn content and heat treatment on microstructures and mechanical properties of Mg-Zn-Mn wrought magnesium alloys. Rare Metal Mat. Eng. 2011, 40, 418-423.

25. Wu, Q.; Yan, H.G.; Chen, J.H.; Xia, W.J.; Song, M.; Su, B. The interactions between dynamic precipitates and dynamic recrystallization in Mg-5Zn-1Mn alloys during hot compression. Mater. Charact. 2020, 160, 110131. [CrossRef]

26. Chen, C.; Chen, J.H.; Yan, H.G.; Su, B.; Song, M.; Zhu, S.Q. Dynamic precipitation, microstructure and mechanical properties of Mg-5Zn-1Mn alloy sheets prepared by high strain-rate rolling. Mater. Design 2016, 100, 58-66. [CrossRef]

27. Xu, C.; Zheng, M.Y.; Chi, Y.Q.; Chen, X.J.; Wu, K.; Wang, E.D.; Fan, G.H.; Yang, P.; Wang, G.J.; Lv, X.Y.; et al. Microstructure and mechanical properties of the $\mathrm{Mg}-\mathrm{Gd}-\mathrm{Y}-\mathrm{Zn}-\mathrm{Zr}$ alloy fabricated by semi-continuous casting. Mater. Sci. Eng. A 2012, 549, 128-135. [CrossRef] 
28. Zhang, D.F.; Zhao, X.B.; Shi, G.L.; Qi, F.G. Influence of extrusion and heat treatment on microstructure and mechanical properties of ZM61 magnesium alloys. Chin. J. Nonferrous Met. 2012, 22, 53-61. [CrossRef]

29. Gao, X.; Nie, J.F. Characterization of strengthening precipitate phases in a Mg-Zn alloy. Scripta Mater. 2007, 56, 645-648. [CrossRef]

30. Oh-Ishi, K.; Hono, K.; Shin, K. Effect of pre-aging and $\mathrm{Al}$ addition on age-hardening and microstructure in Mg-6 wt\% Zn alloys. Mater. Sci. Eng. A 2008, 496, 425-433. [CrossRef]

31. Liu, H.; Yin, R.; Zou, Q.; Zhang, J.; Liu, Z.; Zhang, X. Effects of micro-twin lamellar structure on the mechanical properties and fracture morphology of AZ31 Mg alloy. Mater. Sci. Eng. A 2019, 745, 221-230. [CrossRef]

32. Jiang, Y.; Chen, Y.A.; Fang, D.; Jin, L. Effect of Li on microstructure, mechanical properties and fracture mechanism of as-cast Mg-5Sn alloy. Mater. Sci. Eng. A 2015, 641, 256-262. [CrossRef]

33. Atrens, A.; Song, G.-L.; Cao, F.Y.; Shi, Z.M.; Bowen, P.K. Advances in Mg corrosion and research suggestions. J. Magnes. Alloy 2013, 1, 177-200. [CrossRef]

34. Zhang, X.; Zhang, K.; Li, X.G.; Deng, X.; Li, Y.; Ma, M.L.; Shi, Y. Effect of solid-solution treatment on corrosion and electrochemical behaviors of Mg-15Y alloy in $3.5 \mathrm{wt} . \% \mathrm{NaCl}$ solution. J. Rare Earth 2012, 30, 1158-1167. [CrossRef]

35. Zhang, E.L.; Yin, D.S.; Xu, L.P.; Yang, L.; Yang, K. Microstructure, mechanical and corrosion properties and biocompatibility of Mg-Zn-Mn alloys for biomedical application. Mater. Sci. Eng. C 2009, 29, 987-993. [CrossRef]

36. Verissimo, N.C.; Freitas, E.S.; Cheung, N.; Garcia, A.; Osório, W.R. The effects of Zn segregation and microstructure length scale on the corrosion behavior of a directionally solidified Mg-25 wt.\%Zn alloy. J. Alloy. Compd. 2017, 723, 649-660. [CrossRef]

37. Zuo, J.R.; Hou, L.G.; Shi, J.T.; Cui, H.; Zhuang, L.Z.; Zhang, J.S. Enhanced plasticity and corrosion resistance of high strength $\mathrm{Al}-\mathrm{Zn}-\mathrm{Mg}-\mathrm{Cu}$ alloy processed by an improved thermomechanical processing. J. Alloy. Compd. 2017, 716, 220-230. [CrossRef]

38. Zhao, M.C.; Liu, M.; Song, G.; Atrens, A. Influence of the $\beta$-phase morphology on the corrosion of the Mg alloy AZ91. Corros. Sci. 2008, 50, 1939-1953. [CrossRef]

39. Chowdary, S.; Dumpala, R.; Kondaiah, V. Influence of heat treatment on the machinability and corrosion behavior of AZ91 Mg alloy. J. Magnes. Alloy 2018, 6, 52-58. [CrossRef]

40. Zhang, Y.; Li, J.Y.; Liaw, P.K.; Xu, Y.Z.; Lai, H.Y. Effects of heat treatment on the mechanical properties and corrosion behaviour of the Mg-2Zn-0.2Mn-xNd alloys. J. Alloy. Compd. 2018, 769, 552-565. [CrossRef]

41. Yan, Y.; Cao, H.W.; Kang, Y.J.; Yu, K.; Xiao, T.; Luo, J.; Deng, Y.W.; Fang, H.J.; Xiong, H.Q.; Dai, Y.L. Effects of $\mathrm{Zn}$ concentration and heat treatment on the microstructure, mechanical properties and corrosion behavior of as-extruded Mg-Zn alloys produced by powder metallurgy. J. Alloy. Compd. 2017, 693, 1277-1289. [CrossRef] 